\title{
Anniversary Meeting of the Royal Society
}

\begin{abstract}
$\mathrm{O}^{\mathrm{N}}$ St. Andrew's Day, November 30, the customary anniversary meeting of the Royal Society was held, and Sir Frederick Gowland Hopkins delivered his presidential address. In the course of the address, he referred to the work of the fourteen fellows and four foreign members of the Society who have died since the last anniversary meeting. Speaking of the Report of Council, he stated that a gift of $£ 10,000$ has been recently received at the instance of Prof. P. E. Newberry and Mrs. Newberry from the trustees of the late William Johnston, of Liverpool, for the foundation of a fellowship or studentship for research on problems of health. He also said that, in the last ten years, both the Philosophical Transactions and Proceedings of the Society have doubled in bulk, while the Society's present expenditure on research is nearly ten times that of twenty-five years ago.

At the conclusion of his presidential address, parts of which are printed in this issue (p. 893), Sir Frederick presented the medals for 1935 ; extracts from his remarks in making the presentations are given below.
\end{abstract}

\section{Presentation of Medals}

Copley Medal, awarded to Prof. C. T. R. Wilson

Prof. Charles Thomson Rees Wilson is awarded the Copley Medal for his contributions to the progress of modern physics by his work on the use of clouds in advancing our knowledge of atoms and their properties. How wide the field of his work has been can be seen from the following summary of his researches. He studied the phenomena of condensation of vapour to form drops by the use of expansion apparatus-which he designed. He discovered the existence of 'rainlike' and 'eloudlike' condensation of water vapour, and measured the corresponding supersaturations and critical expansions. $\mathrm{He}$ also measured the supersaturations re. quisite to produce condensation of water vapour on ions of both signs produced in various ways. $\mathrm{He}$ devised and constructed various types of electrometers, and with them and with his cloud apparatus demonstrated the so-called natural ionisation of air and other gases. With a new form of expansion apparatus, he photographed the tracks of ionising particles and radiations traversing gases.

Prof. Wilson next developed methods of measurement which he applied to the study of thunderstorm electricity. In this work the main phenomena relating to the electric field changes produced by lightning discharges were observed for the first time, studied quantitatively, and the principles of their interpretation outlined.

Prof. Wilson further extended the use of the cloudchamber method. Stereoseopic methods of photographing ionisation tracks in the cloud chamber were applied successfully to the investigation of the properties of photo-electrons and Compton recoil electrons, including their ranges. In recent years, he has continued to make numerous and important contributions to the study of atmospheric electricity and, by introdueing important improvements and modifications into his cloud-chambers, he has greatly extended their use.

\section{A Royal Medal, awarded to Prof. C. G. Darwin}

A Royal Medal is awarded to Prof. Charles Galton Darwin for his researches in mathematical physics, especially in quantum-mechanics, optics and statistical mechanics. His papers on the reflection of $\mathrm{X}$-rays are now regarded as the fundamental researches on the subject.

In a series of papers on statistical mechanics, written in collaboration with R. H. Fowler, he published a new mathematical technique by which the relation of thermodynamies to statisties was placed on a satisfactory basis, and the way was opened for extensive subsequent developments.

Perhaps the most original and influential of Darwin's papers have been those concerned with quantum-mechanies. The quantum theory of the motion of an electron in an electromagnetic field, as it had been developed before 1925, gave results not in accordance with experiment. To obviate this, in 1925 , the assumption was introduced that the electron has a mechanical angular momentum and a magnetic moment; but this conception did not admit of the application of wave-theory, since the waves corresponding directly to such an electron would be in space of six dimensions. It was Darwin who in February 1927 put forward the idea which led ultimately to the solution of these difficulties; he assumed that, just as there are two independent polarised components in a wave of light, so there are two independent components in the wave of an electron. He then constructed a pair of equations to represent the fine structure of the hydrogen spectrum, obtaining all the levels correctly except the $s$-levels, and showed how the equations could be expressed in vectorial form, so that, as he expressed it, the electron was a vector wave.

Among the quantum papers is also numbered the celebrated memoir on "Free Motion in Wave Mechanics", in which he took up the general question of aperiodic phenomena and dealt with it in masterly fashion, the principles of description and interpretation which are now universally accepted being formulated and applied to the free motion of electrons and atoms in various types of field.

\section{A Royal Medal, awarded to Dr. A. Harker}

A Royal Medal is awarded to Dr. Alfred Harker as the greatest British petrologist since that subject became a science. In 1886 he published a paper on slaty cleavage, which added considerably to the better understanding of the nature and laws of cleavage phenomena. His next important contribution was the Sedgwick Prize Essay of 1889 on the Bala Volcanic Series of Carnarvonshire. In collaboration with his colleague, J. E. Marr, he published a notable work on the Shap granite and associated rocks.

It is probably true to say that Harker's greatest achievement is the geological mapping of the island of Skye in 1895-1901, the results of which were published as a memoir of the Geological Survey in 190t. This monumental work has had a very wide influence upon the science of petrology : in this memoir and in the subsequent memoir on the Smaller 
Islands of the Inner Hebrides, Harker set a high standard of work both in the field and in the laboratory. His book on the "Natural History of Igneous Rocks", published in 1909, has been described as "a work which has had a greater effect than any geological publication in the last fifty years". $\mathrm{He}$ has also made contributions of great value to the subject of differentiation of rock magmas, etc. His latest book on "Metamorphism", published in 1932, is the best contribution to the subject written in any language.

\section{Davy Medal, awarded to Prof. A. Harden}

Prof. Arthur Harden is awarded the Davy Medal in recognition of his distinguished work in biochemistry and especially of his fundamental discoveries in the chemistry of alcoholic fermentation. In 1904, in collaboration with his colleague W. J. Young, he showed that the alcoholic ferment of active cell-free yeast juice, the preparation of which had been achieved a few years earlier by $\mathrm{E}$. and $\mathrm{H}$. Buchner, could be separated into two components, a thermolabile non-dialysable enzyme complex and a thermostable dialysable co-enzyme, both of these being essential for the fermentation of sugar. They observed that the fermentation of sugars by this yeast juice was profoundly affected by an addition of inorganic phosphate, and followed up this discovery by a detailed and systematic investigation of the carbon balance, from which they showed that, for each hexose molecule broken down to carbon dioxide and alcohol, another molecule became esterified with phosphoric acid. From the fermentation products, hexosediphosphoric and hexosemonophosphoric esters were afterwards isolated by Harden and his colleagues. These discoveries have been the foundation upon which much of our present knowledge of the intermediate changes in the enzymic breakdown of carbohydrate has been established.
Harden has made important contributions to our knowledge of chemical reactions effected by bacterial enzymes, especially those concerned in carbohydrate metabolism. He has also taken an active part in the development of vitamin research in Great Britain, while as editor of the Biochemical Journal since 1911 he has influenced deeply the development of this branch of chemistry.

\section{Hughes Medal, awarded to Dr. C. J. Davisson}

A Hughes Medal is awarded to Dr. Clinton Joseph Davisson for his discovery that electrons are diffracted like waves of light. Like many other discoveries, this one disclosed itself gradually; but its origin can certainly be traced to some experiments on the scattering of electrons by nickel made by Davisson and Kunsmann in 1921. Davisson recognised at the time that the observed effects did not harmonise with the existing theories of matter and electrons. Owing to the polycrystalline nature of the metals investigated, the correct interpretation to be put upon the results was not at all clear. Davisson fully recognised the importance of this discrepancy, and this he and his assistants proceeded to investigate with great pertinacity and skill.

Towards the end of 1926, Davisson and Germer succeeded in making similar experiments with a single metallic crystal surface, so that the results were simple enough to be interpreted easily. It was then at once seen that the electrons were diffracted like waves of light of the wave-length required by the theory which had in the meanwhile been put forward by $\mathbf{M}$. de Broglie towards the end of 1924 . The first announcement of Davisson and Germer's results was published in NATURE of April 16, 1927. This publication was the first clear experimental proof of the wave character of the electron.

Davisson has also made important contributions to thermionies.

\section{Thixotropic Colloids}

\begin{abstract}
A
PUBLIC lecture on some recent developments of colloid science was delivered at Queen Mary College, London, on November 29 by Prof. $\mathrm{H}$. Freundlich.

Prof. Freundlich pointed out that, whilst it has long been known that a solid gel, such as a gelatin gel, may be liquefied to a sol on heating, and that it returns reversibly to the state of a gel on cooling, investigators in colloid science scarcely realised until recently that an isothermal, reversible, sol-gel transformation is also very frequent. Many gels may be liquefied by shaking or stirring and set to a gel again, in a definite time, when left to themselves. This phenomenon is called thixotropy. It is found not only in true sols and gels (of oxides like $\mathrm{Al}_{2} \mathrm{O}_{3}$. $\mathrm{Fe}_{3} \mathrm{O}_{3}$, of gelatin, etc.), but also in concentrated suspensions of coarser particles (of clays, bentonite, etc.). In many cases, thixotropy may be regarded as a first, reversible stage of coagulation, causing the whole sol to unite to one large flake, so to say, which is able to enclose all the liquid present.

Under suitable conditions, some thixotropie sols may be solidified much more rapidly by a gentle, regular movement, a phenomenon called rheopexy. Thus there is a distinct difference between the
\end{abstract}

liquefying action of strong and irregular movement and the solidifying influence of regular, weak vibrations and similar kinds of movement.

Thixotropy generally, perhaps always, involves a loose packing of the particles. The plastic behaviour of such masses also depends upon their loose packing. Hence thixotropy and plasticity are in opposition to Osborne Reynolds's dilatancy, which involves close packing ; moist, pure quartz sand shows dilataney, becoming hard and dry when displaced by an external force, and returning to its original, moist state when this force ceases to act. Foreign substances, such as clay, etc., when added to the sand, form waterbinding layers round the particles, thus causing loose packing and thixotropy. A case of quicksand was found the thixotropic behaviour of which was caused by the presence of a fine, clay-like substance; this may be a fairly frequent occurrence. Moulding sands are also plastic and thixotropic because they contain clay and iron compounds.

In many other technical processes (plastics, paints, drilling fluids in the petroleum industry, etc.) thixotropy turns out to be an important factor. Protoplasm is frequently thixotropic, or may readily become so in the course of biological processes. 